\title{
Zinc Supplementation in NFkB and Mucosal Intestinal Repair During LPS-Induced Sepsis in Rodents
}

\author{
Martono T. Utomo ${ }^{1}$, Subijanto M. Sudarmo ${ }^{1}$, Ketut Sudiana ${ }^{2}$ \\ ${ }^{1}$ Department of Child Health, Faculty of Medicine, Universitas Airlangga, Surabaya, Indonesia \\ ${ }^{2}$ Department of Pathology Anatomy, Faculty of Medicine, Universitas Airlangga, Surabaya, Indonesia \\ Corresponding author : mrmartono73@gmail.com
}

\begin{abstract}
Background: Severe sepsis increases pro-inflammatory cytokines and damage to the intestinal mucosa, causing systemic translocation to the commensal bacteria. Low zinc levels were also found in patients with sepsis.

Objective: This study aims to explain the mechanisms of sepsis improvement after zinc administration by measuring NFkB expression and mucosal intestinal repair.

Material and Methods: Samples of 40 rats were randomized into 4 group of Control, LPS, LPS-Zinc, and Zinc . Blood sampling in 2-hour after LPS or placebo administration to measure zinc level. Zinc was administered in LPS-Zinc and Zinc group, placebo was given in other groups. Blood sampling in 8, 24 and 72 hours to measure NFkB monocyte expression by sandwich-ELISA method and in 72 hours also measured the zinc content by AAS method and jejunal tissue by SEM analysis. Statistical analyzes used were one-way Anova, Kruskall Wallis, Mann-Whitney, Paired-t tests, Wilcoxon Signed Rank Test and path analysis.

Results: There were decreased in NFkB monocyte expression in the LPS-Zinc group compared to the LPS group.

Conclusion: Improvement of intestinal mucosa occured in LPS-Zinc group. The administration of zinc improves the condition of sepsis and improving intestinal mucosa (villi structure of jejunum).
\end{abstract}

Keywords: Zinc ; Sepsis ; Cytokine ; Intestinal mucosal

\section{Introduction}

Sepsis remains as a world health problem. Multicentre studies involving developed and developing countries found that mortality due to severe sepsis in children in hospital was still high, namely: $25 \% .{ }^{1}$ A study in Southeast Asia involving 13 public hospitals in 3 countries including Indonesia found $2 \%$ of sepsis deaths with $28 \%$ incidence of severe sepsis in children and $13 \%$ of sepsis deaths with $68 \%$ incidence of severe sepsis in adults. ${ }^{2}$ Research at Dr. Soetomo General Hospital showed death due to sepsis was $16.7 \%$, severe sepsis $27.08 \%$, and septic shock $14.58 \%,{ }^{3}$ while in Cipto Mangunkusumo Hospital, from $10.3 \%$ of sepsis cases 47,8\% associated with death. ${ }^{4}$ Low plasma zinc levels were found in severe and critical sepsis patients in children and adults. ${ }^{5,6,7}$ This actively demonstrate that low zinc levels in patients with severe and critical sepsis are still a problem.

Sepsis symptoms worsened when the host's immune response to infection is amplified and dysregulated. Resulting in transient hypotension symptoms, decreased urine production, thrombocytopenia which can result in multiple organ dysfunction. ${ }^{8}{ }^{8}$ Sepsis begins when bacteria enter the bloodstream and are recognized by the immune system through the pattern recognition receptor (PRR) which can detect pathogen-associated molecular patterns (PAMPs) from bacteria. The PRR bond with the PAMP triggers a signal cascade that activates the NFkB and AP-1 via MyD88 or TICAM-1. NFkB induces cytokines that cause symptoms of tachycardia, tachypnea, and fever. Activation of NFkB also causes injury to blood vessels. Blood vessel damage increased the vascular permeability that worsens the sepsis symptoms. ${ }^{10}$ 
Proinflammatory cytokines increased intestinal permeability and bacterial translocation occur in sepsis. ${ }^{11,12}$ The bacterial translocation happens through two mechanisms: transcellular through enterocytes or paracellular through tight junctions. The study found that E. Coli and Proteus mirabilis in enterocytes showed a transcellular pathway through enterocytopinocytosis and bacterial invasion. Translocation through tight junctions can occur due to damage to the cytoskeleton and microtubular such as endotoxin. ${ }^{13}$

Sepsis handling is still not optimal, shown by high mortality. ${ }^{1}$ Zinc administration can improve systemic immune response and repair of the intestinal mucosa. Zinc suppresses the activation of monocyte NFKB which further suppresses TNF- $\alpha .{ }^{4}$ Zinc reduces oxidative stress and ROS production because zinc functions as a scavenger enzyme. ${ }^{15}$ Zinc also decreases levels of CRP, lipid peroxidase, and proinflammatory cytokines. ${ }^{16}$ Zinc through the MAPK pathway and TGF $\beta-1$ signaling increases intestinal permeability thereby preventing bacterial translocation. ${ }^{17}$ The mechanism of action of zinc in sepsis through improved regulation of cytokines and intestinal mucosa in experimental animals exposed to intravenous lipopolysaccharide (LPS) as a model of sepsis is still unclear.

This study seeks to reveal the repair mechanism of sepsis after zinc administration by measuring NFkB and intestinal mucosal repair. This study used rats because it requires a sepsis model with intravenous LPS exposure, serial blood collection, and intestinal samples that can't be done in humans.

\section{Methods}

\subsection{Preparation of animal study}

This was an experimental study with a completely randomized design. Ethical clearance was given, number 700-KEP-UB. We use healthy male Sprague-Dawley rats (Rattus norvegicus) aged 10-12 weeks and excluded if there were congenital abnormalities at birth. The rats were acclimatized for two weeks at the Institute of Biosciences, Brawijaya University before being used. Feeding standard pellets and drinking water ad libitum and the husks are changed every two days. In total, 40 rats were used for our animal study then randomly divided into four group. Two group will be given a placebo, and two other as a sepsis animal model.

\subsection{LPS Administration}

Stimulation of LPS E. Coli serotype O111: B4 at a dose of $10 \mathrm{mg} / \mathrm{kg}$ rats body weight intravenous given to the two groups of the sepsis animal model. To facilitate intravenous administration of rats were injected with ketamine $0.1 \mathrm{~mL}$ intramuscular.

\subsection{Serum Zinc Levels}

The zinc sulfate solution was given by adding $9 \mathrm{~mL}$ of aquadest to $1 \mathrm{~mL}$ of zinc sulfate drop $(10 \mathrm{mg} / \mathrm{mL})$, the dose was $4.65 \mathrm{mg} / \mathrm{kg} \mathrm{BW}$ for rats. A sample of rat blood was taken from the tail at the $2 \mathrm{nd}$ hour as much as $2 \mathrm{~mL}$ for zinc examination and another $2,5 \mathrm{ml}$ blood samples at the $8^{\text {th }}$ and $24^{\text {th }}$ hours for ELISA and ICC tests, while at $72^{\text {nd }}$ hour we collect blood samples from the rat aorta. Then divided into samples with EDTA (centrifuged at $6,000 \mathrm{G}$ for 10 minutes at $25^{\circ} \mathrm{C}$ within 30 minutes after being collected and stored in a $-20^{\circ} \mathrm{C}$ refrigerator) and without EDTA (stored in a $-20^{\circ} \mathrm{C}$ refrigerator). Measurement of zinc levels in serum using the Atomic Absorption Spectroscopy (AAS) method for its specificity, sensitivity, accuracy and less cost. ${ }^{18} \mathrm{We}$ begin with making a standard zinc solution of $1000 \mathrm{mg}$ zinc/liter by diluting $10 \mathrm{~mL}$ of nitric acid to $50 \mathrm{~mL}$ by adding $1,000 \mathrm{~g}$ of zinc, diluting it again to $100 \mathrm{ml}$. As much as $1 \mathrm{~mL}$ of standard zinc mixed with a 5/95 to 100 mL glycerol water solution, shaken 16 times, then 1, 2, 3, $4 \mathrm{~mL}$ were taken into $100 \mathrm{~mL}$ volume flask and added with a $5 / 95$ glycerol/water solution. Solutions $(0.1,0.2,0.3$, and $0.4 \mathrm{mg}$ zinc per liter) were associated with plasma zinc concentrations of 500,1,000,1,500, and 2,000 $\mathrm{g}$ of zinc per liter. We use $1.2 \mathrm{~mL}$ of blood with a drop of sodium citrate, then centrifuged $900 \mathrm{G}$ for 20 minutes.

Take $0.5 \mathrm{~mL}$ of plasma and add $2 \mathrm{~mL}$ of de-ionized water mixed for 30 seconds, using spectrophotometry 
to read the results by comparing with standard zinc solutions. ${ }^{19}$

Table 1. Mean Rats Body Weight in four groups

\begin{tabular}{llllll}
\hline \multirow{2}{*}{ Group } & $\mathrm{n}$ & \multicolumn{2}{c}{ Body Weight $(\mathrm{g})$} & & \\
& & Mean & Minimum & Maximum & $\mathrm{P}$ \\
\hline Control & 5 & 221,40 & 213 & 229 & \\
LPS & 5 & 240,80 & 225 & 253 & \\
LPS- & 5 & 226,60 & 208 & 256 & 0,336 \\
Zinc & & & & & \\
Zinc & 5 & 232,80 & 202 & 263 & \\
\hline
\end{tabular}

Table 2. Serum zinc levels at $2 \mathrm{~h}$ and $72 \mathrm{~h}$ after LPS E. Coli administration

\begin{tabular}{|c|c|c|c|c|}
\hline Group & $\mathrm{n}$ & $\begin{array}{l}\text { Zinc Levels } \\
2 \mathrm{~h}\end{array}$ & $72 \mathrm{~h}$ & $\mathrm{P}$ \\
\hline Control & 5 & $\begin{array}{l}0,87 \pm 0,09 \\
(0,75-0,97)\end{array}$ & $\begin{array}{l}0,91 \pm 0,22^{a} \\
(0,57-1,19)\end{array}$ & 0,670 \\
\hline LPS & 5 & $\begin{array}{l}0,62 \pm 0,21 \\
(0,42-0,97)\end{array}$ & $\begin{array}{l}1,14 \pm 0,24^{\mathrm{a}} \\
(0,94-1,54)\end{array}$ & $0,039 * *$ \\
\hline $\begin{array}{l}\text { LPS- } \\
\text { Zinc }\end{array}$ & 5 & $\begin{array}{l}0,75 \pm 0,06 \\
(0,71-0,86)\end{array}$ & $\begin{array}{l}0,99 \pm 0,07^{\mathrm{a}} \\
(0,94-1,11)\end{array}$ & $0,043 * *$ \\
\hline Zinc & 5 & $\begin{array}{l}0,87 \pm 0,18 \\
(0,62-1,12)\end{array}$ & $\begin{array}{l}1,49 \pm 0,17^{b} \\
(1,33-1,74)\end{array}$ & $0,001 * *$ \\
\hline $\mathrm{p}$ & & 0,073 & $0,001 *$ & \\
\hline
\end{tabular}

\subsection{Monocytes NfKB Activities Immunocytochemical Examination}

We isolated rat aortic blood monocytes in an EDTA tube. The $15 \mathrm{~mL}$ tube is filled with a 1: 1 ficoll solution with the volume of blood to be used and then centrifuged at a speed of 1,400 rpm, 33 minutes at room temperature. Pellets were washed using PBS (Phosphate Buffer Saline) as much as $5 \mathrm{x}$ the volume and centrifuged at 1,200 rpm, 10 minutes, at room temperature then added with complete RPMI (Roswell Park Memorial Institute) medium. A sterile coverslip is prepared for insertion into the well. $200 \mu 1$ of the gelatincoating solution was added and the coverslip was incubated for 10 minutes at room temperature, then the gelatin-coating solution was removed and the coverslip was dried for 15 minutes.

After isolation, monocyte cells with positive NFkB activity were stained using $4 \%$ formaldehyde for 20 minutes, washed with PBS-T (Phosphate Buffer Saline-Tween) for 2 minutes 3 times, then added 3\% Hydrogen Peroxide for 10 minutes, and washed with distilled water followed by $10 \%$ addition. FBS (Fetal Bovine Serum) in PBS for 10 minutes then dried without washing. After that, NFkB primary antibody (rabbit polyclonal antirat NFkB p65 antibody) was added (1: 500) for 1 hour at $37^{\circ} \mathrm{C}$ then washed using PBS-T 3x @ 2 minutes and added 2 drops of reagent 1 solution per well and incubated for 30 minutes. Washed using PBS-T $3 \mathrm{x} @ 2$ minutes followed by the addition of 2 drops of reagent and incubated for 30 minutes. Washed thrice using PBS-T for 2 minutes. Then add a solution of chromogen (1-2 drops of reagent 3B put into $1 \mathrm{~mL}$ of reagent $3 \mathrm{~A}$, vortex until well blended) as much as 2 drops per well. After that, rinsing was carried out and added with a solution of counterstained hematoxylene (50 $\mu \mathrm{l}$ in $1 \mathrm{~mL}$ tap water) of $100 \mu \mathrm{l}$ per well for 1 minute, rinse for 2 minutes. Add PBS for 1 minute and rinse. After the process is complete and the slides are dry, mount the slides with glues. We used the Olympus BX53 series microscope to analyzed at 600x magnification. Microscope images are taken with a special camera (DP72 camera). Monocyte counting with NFkB activation compared to all fields of view was done with Immunoratio software. 


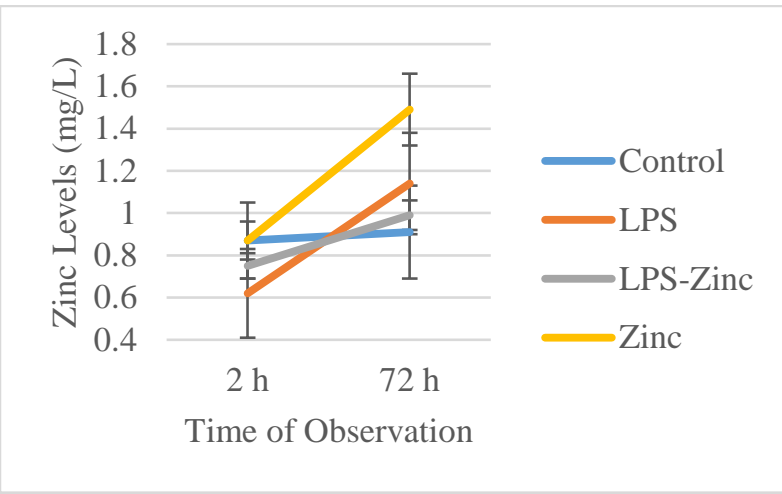

Fig 1. Comparison of zinc levels at $2 \mathrm{~h}$ and $72 \mathrm{~h}$ in 4 groups

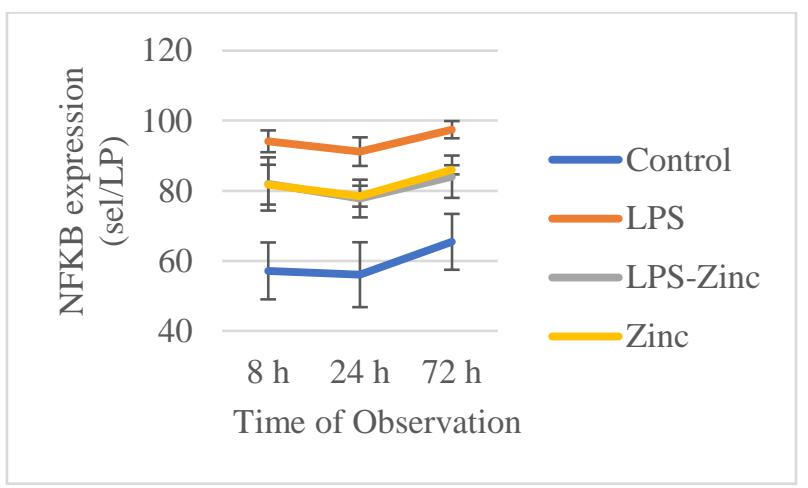

Fig 2. Comparison of monocyte NFkB expression in 4 groups

\subsection{Scanning Electron Microscope (SEM) Examination on Jejunum Tissue}

The jejunal tissue was collected in $72^{\text {nd }}$ hour after LPS administration. jejunum segments which had been stored at $-20 \mathrm{oC}$, were liquefied and fixed with glutaraldehyde were cut longitudinally and placed in a box covered with paraffin wax. The mucosal surface faces upwards and is carefully washed and then cut into $5 \mathrm{~mm}$. Samples were fixed for 2 hours at $4^{\circ} \mathrm{C}$ in $5 \%$ glutaraldehyde in $0.05 \mathrm{M}$ cacodylate buffer at $\mathrm{pH} 7.4$, rinsed with cacodylate buffer, after fixation of $1 \%$ osmium tetroxide, and dehydrated with alcohol. Dehydrated samples were dried after two immersion of 1,1,1,3,3,3-hexamethyldisilazan (Aldrich), then attached to a glass object with carbon adhesive tabs or silver paint, gold-coated (Edwards Sputter Coater), scanned using a JeolS100 electron microscope with 750x magnification and a secondary detector. ${ }^{20}$ 


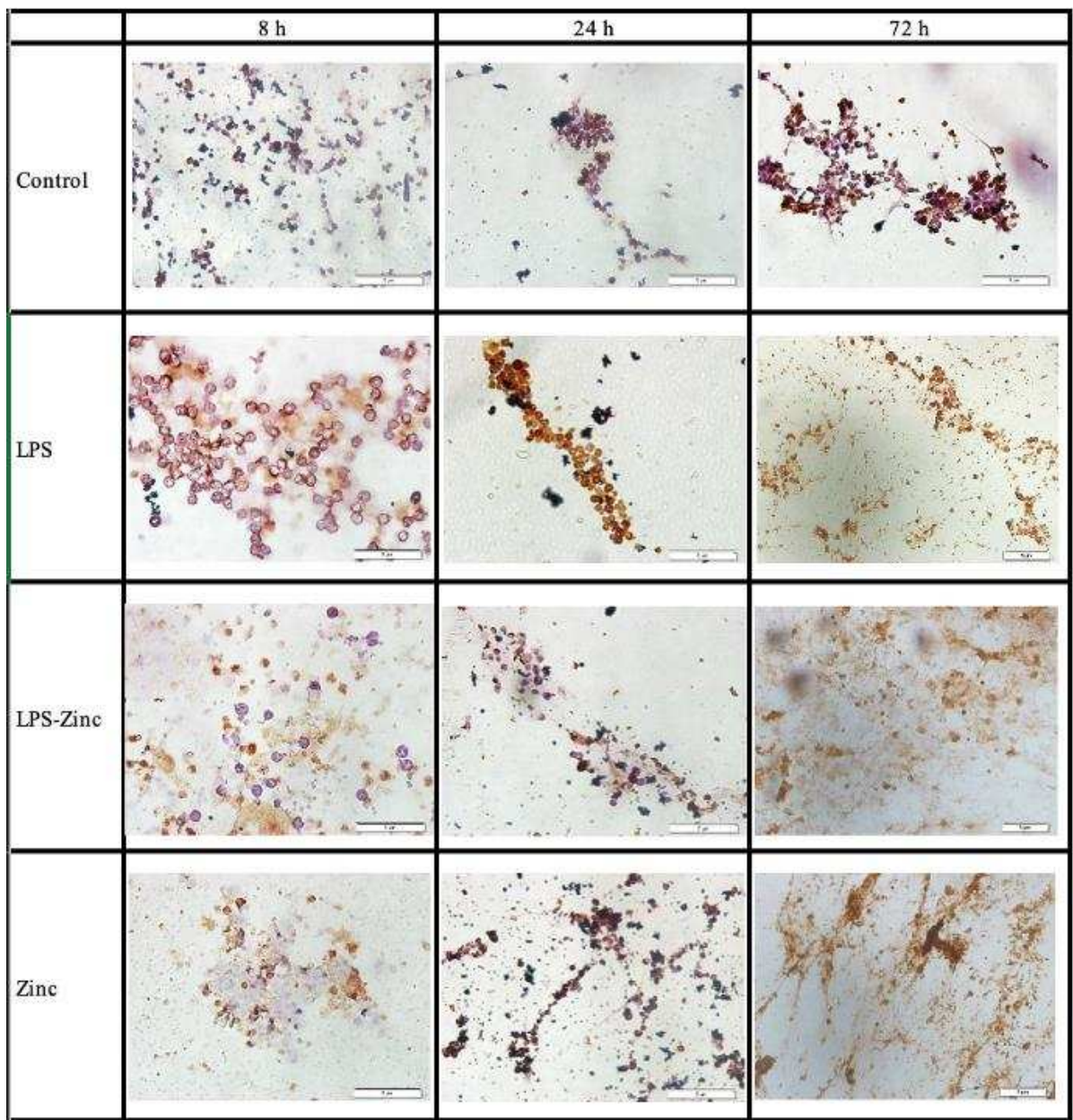

Fig 3. Microscopic image of NFkB expression on monocytes using a $600 \mathrm{x}$ magnification light microscope.

\subsection{Statistical Analysis}

We analyzed zinc levels and intestinal mucosal damage with descriptive analysis. One-way ANOVA was used to analyze the difference between mean and standard deviation (SD) levels of zinc NFkB by first doing a normality test of all the dependent variables on all group. Comparison of group data at $8^{\text {th }}, 24^{\text {th }}$, and $72^{\text {nd }}$ hour measurements were performed with Same Subject ANOVA analysis if the distribution was normal and Friedman's ANOVA if the distribution wasn't normal. The zinc action mechanism was analyzed using Path Analysis $(\alpha=0.05)$.

\section{Result}

In this study, we divided forty rats into four groups of ten each: the control group (C), the LPS group (L), the LPS-Zinc group (LZ), and the Zinc group (Z). Table 1 shows that there's no difference in body weight between groups before the treatment is given ( $p>0.05)$. The LPS and LPS-Zinc groups received intravenous 
administration of LPS E. Coli. The control and zinc groups with aqua dest placebo. Blood was collected (2.5mL) at the 2 nd hour on five rats in each group to measure zinc levels. The aqua placebo was given to the control group and the LPS group at the $2^{\text {nd }}, 24^{\text {th }}$, and $48^{\text {th }}$ hours. We give zinc $4.65 \mathrm{mg} / \mathrm{kg} \mathrm{BW}$ in the form of zinc sulfate solution for $10 \mathrm{mg} / \mathrm{mL}$ diluted to $1 \mathrm{mg} / \mathrm{mL}$ in the LPS-Zinc group and the zinc group at $2^{\text {nd }}, 24^{\text {th }}$, and $48^{\text {th }}$ hours. Two death occurred in the LPS group at the $8^{\text {th }}$ and $24^{\text {th }}$ hours.

Table 3. NFкB Monocytes Expression in 8 h, 24 h, 72 h in 4 groups

\begin{tabular}{|c|c|c|c|c|c|}
\hline \multirow{3}{*}{ Groups } & \multirow{3}{*}{$\mathrm{n}$} & \multicolumn{3}{|c|}{ Number of Monocytes } & \multirow{3}{*}{$\mathrm{P}$} \\
\hline & & \multicolumn{3}{|c|}{ Expressing NFKB } & \\
\hline & & $8 \mathrm{~h}$ & $24 \mathrm{~h}$ & $72 \mathrm{~h}$ & \\
\hline \multirow{4}{*}{ Control } & & 57,12 & 56,04 & 65,42 & \multirow{3}{*}{0,247} \\
\hline & 5 & $\pm 8,12^{\mathrm{a}}$ & $\pm 9,27^{\mathrm{a}}$ & $\pm 7,98^{\mathrm{a}}$ & \\
\hline & 5 & $\begin{array}{c}(44,80- \\
6740)\end{array}$ & $\begin{array}{r}(45,00- \\
65,30)\end{array}$ & $\begin{array}{c}(59,20- \\
77,95)\end{array}$ & \\
\hline & & 94,12 & 91,17 & 97,44 & \multirow{5}{*}{0,077} \\
\hline \multirow{4}{*}{ LPS } & 5 & $\pm 3,11^{\mathrm{c}}$ & $\pm 4,08^{c}$ & $\pm 2,46^{\mathrm{c}}$ & \\
\hline & 5 & $(91,20-$ & $(86,55-$ & $(93,60-$ & \\
\hline & & $99,10)$ & $95,80)$ & $99,60)$ & \\
\hline & & 81,94 & 77,78 & 84,01 & \\
\hline \multirow{3}{*}{$\begin{array}{l}\text { LPS- } \\
\text { Zinc }\end{array}$} & 5 & $\pm 7,60^{\mathrm{b}}$ & $\pm 5,38^{b}$ & $\pm 6,04^{b}$ & \multirow{3}{*}{0,092} \\
\hline & $J$ & $(70,50-$ & $(68,90-$ & $(74,65-$ & \\
\hline & & $90,20)$ & $82,40)$ & $91,00)$ & \\
\hline \multirow{4}{*}{ Zinc } & & 81,74 & 78,45 & 85,98 & \multirow{5}{*}{$0,041 * *$} \\
\hline & 5 & $\pm 5,69^{b}$ & $\pm 2,98^{b}$ & $\pm 1,31^{b}$ & \\
\hline & & $(71,80-$ & $(73,20-$ & $(84,60-$ & \\
\hline & & $85,90)$ & $80,40)$ & $87,60)$ & \\
\hline $\mathrm{p}$ & & $0,001 *$ & $0,001 *$ & $0,000 *$ & \\
\hline
\end{tabular}

After two hours of administration of LPS E. Coli $10 \mathrm{mg} / \mathrm{kg}$ BW intravenously, we found zinc deficiency (normal zinc levels were 84 - $159 \mu \mathrm{g} / \mathrm{dL}$ ) in LPS and LPS-Zinc groups. There were differences between the Zinc group and the other three groups (Control, LPS, and LPS-Zinc) after $72^{\text {nd }}$ hours. The difference in zinc levels at the second and $72^{\text {nd }}$ hours shows that three days of zinc administration can increase zinc levels (Table 2 and Figure 1). The monocytes NFkB expression analysis in the LPS group was higher than the other three groups at 8, 24, and 72 hours. Showed that zinc inhibited NFkB expression. Meanwhile, the control group was the lowest, compared to the other three groups (Table 3 and Figure 2). The monocytes' NFkB was brown in monocytes on a microscope image with 600x magnification (ocular 10x and objectively 60x), shown in Figure 3.

SEM examination of the jejunal mucosa in the experimental control group showed high jejunal villi with sufficient epithelial cell density, dense gaps between villi and regular villi arrangement (Figure 4). In the LPS group, jejunal damage was found, characterized by cell edema and wider cell gaps (Figure 5). The jejunal mucosa in the LPS-Zinc group was similar to the control group: the villi were tall and dense, a narrow gap between the villi, and the epithelial arrangement was regular (Figure 6). In the Zinc group, we found damage in the form of cell edema, loose villi spacing, and irregular epithelial arrangement (Figure 7). 


\section{Discussion}

This study aims to reveal the action mechanism of zinc in sepsis-induced LPS E. Coli. The concept is proinflammatory cytokines induced by LPS E. Coli through activation of NFkB monocytes and damage to the jejunal mucosa as a result of sepsis. Activation of NFkB monocytes causes an increase in proinflammatory cytokines which cause tissue and intestinal mucosal damage. We use $10 \mathrm{mg} / \mathrm{mL}$ zinc sulfate solution diluted to $1 \mathrm{mg} / \mathrm{mL}$ at a dose of $2 \mathrm{mg} / \mathrm{kg}$ in humans equivalent to $4.65 \mathrm{mg} / \mathrm{kg}$ BB in mice which functions as a proinflammatory cytokine suppressant, increases anti-inflammatory cytokines, and bowel protection in sepsis. This study compared the LPS group with the control group to see the changes that occur in sepsis when compared to normal conditions. The LPS-Zinc group was compared with the LPS group to see the effect of zinc administration on sepsis. The zinc group was used to see the effect of zinc administration on normal conditions by comparing it with the control group.

Two hours after injection of intravenous LPS E. Coli, the blood zinc levels in the LPS and the LPS-Zinc group were lower than the group without injection; the control and zinc groups. The dose of LPS used in this study was $10 \mathrm{mg} / \mathrm{kg}$ body weight intravenously as used in a previous study by Utomo et al. In a study on Zinc Supplementation in Cytokine Regulation During LPS-induced Sepsis in Rodent. ${ }^{21}$ The reduction in zinc levels 2 hours after administration of LPS in the LPS and LPS-Zinc groups in this study was not as large as the reduction in plasma zinc levels in the septic and critical conditions in the previous study (45-48 $\mu \mathrm{g} / \mathrm{dL})$. 5,6,7

In this study, the average zinc level in the LPS group was $0.62 \mathrm{mg} / \mathrm{L}$ or $62 \mu \mathrm{g} / \mathrm{dL}$, and in the LPS-Zinc group, the mean zinc level was $0.75 \mathrm{mg} / \mathrm{L}$ or $75 \mu \mathrm{g} / \mathrm{dL}$ which was included in zinc deficiency with normal values of zinc levels. $84-159 \mu \mathrm{g} / \mathrm{dL},{ }^{22}$ whereas in the control and zinc groups normal zinc levels were found although there was no difference with the LPS and LPS-Zinc groups. This could be because in this study, the intravenous LPS E. Coli did not cause severe sepsis symptoms. Low zinc levels in sepsis were found in patients with severe and critical sepsis in children and adults which are associated with mortality. ${ }^{5,6,7}$

The 72-hour increase in zinc levels in the LPS group indicated a shift in intracellular to extracellular zinc and the use of zinc by monocytes as signal transduction of NFkB for proinflammatory cytokines. Zinc monocyte levels detected in serum due to centrifugation. Zinc is needed as a second messenger in monocytes so that there is an increase in intracellular zinc levels in monocytes during stimulation of the FC receptor $1{ }^{23}$ In the LPSZinc group, the 72-hour zinc level was not different from the control group because zinc was a scavenger enzyme and anti-inflammatory. The examination of zinc levels using the AAS method reflects the total serum zinc level but does not distinguish between free and albumin-bound zinc levels. There is a decrease in total serum zinc levels, free zinc, and zinc-binding capacity by albumin in a state of sepsis. Three days of zinc administration showed a difference in plasma zinc levels in the control and the zinc group at 72 hours. The zinc levels at the second hour in the control group and the zinc group were still within normal limits. The zinc levels increases occurred at the 72nd hour in the zinc group. It is the same as other studies on giving zinc fortification to the rat's diet for 3 days can increase zinc levels in the zinc deficiency group to normal zinc levels. ${ }^{24}$

Significantly increased levels of NFKB were found in experimental animals that received an intravenous injection of LPS E. Coli. The administration of LPS increases the levels of NFkB through activation of the MyD88 pathway which recruits IRAK-1 and IRAK4- which phosphorylate TRAF6 resulting in activation of complex IKK and phosphorylation of IkB so that NFkB separate from IkB and go to the cell nucleus. ${ }^{25}$ The administration of zinc in this study could significantly reduce the NFkB p65 levels in the group given LPS E. Coli was shown by a significant difference in NFkB expression between the LPS and LPS-Zinc groups: a lower NFkB expression in the LPS-Zinc group at 8,24 , and 72 hours. Other studies stated that zinc reduces NFkB activation through the activation of protein A20 which inhibits NIK (nuclear factor-kB inducible kinase) that activates IKK (I Kinase) and causes NFB activation. ${ }^{26}$ The higher comparison of monocyte NFkB expression in the zinc group compared to the control showed the effect of zinc on monocyte cells. Giving zinc under normal conditions (in this study without giving LPS E. Coli) can increase NFkB expression in monocytes. Previous 
studies also showed an increase in NFkB expression in cells exposed to zinc but in HUT-78 (Th0) cells. The upregulation mechanism of NFkB activation is through phosphorylation of $\mathrm{IkB} .^{27}$

The proinflammatory cytokine response to single doses of intravenous LPS E. Coli can last up to 72 hours due to damage to the intestinal mucosa resulting in systemic translocation of intestinal bacteria. The translocation of these bacteria aggravates sepsis symptoms. ${ }^{11,12,28}$ In this study, there was damage to the jejunal mucosa in the experimental animal group injected with intravenous LPS. Zinc administration can repair the jejunal mucosal damage in the group injected with intravenous LPS. In the previous studies, zinc can improve the tight junction and barrier function of intestinal epithelial cells. ${ }^{29}$ Giving zinc to intestinal cell cultures can induce HSp70 mRNA expression that improves the intestinal epithelial barrier. ${ }^{30} \mathrm{We}$ did not examine the HSP70 blood levels therefore we can not describe the effect of HSP70. Some literature said there was a protective effect of HSP70 on the intestinal barrier, and zinc administration could increase HSP70. Zinc inhibits pathways on NFkB at 8, 24, and 72 hours. The zinc inhibition pathway on NFkB activation at 72 hours is not directly but via TGF- $\beta$. Administration of zinc under normal conditions can increase the activity of NFkB and damage to the jejunal mucosa. This study's limitation is that the cytokines examined in this study cannot be determined to come from monocytes alone and can come from other sources.

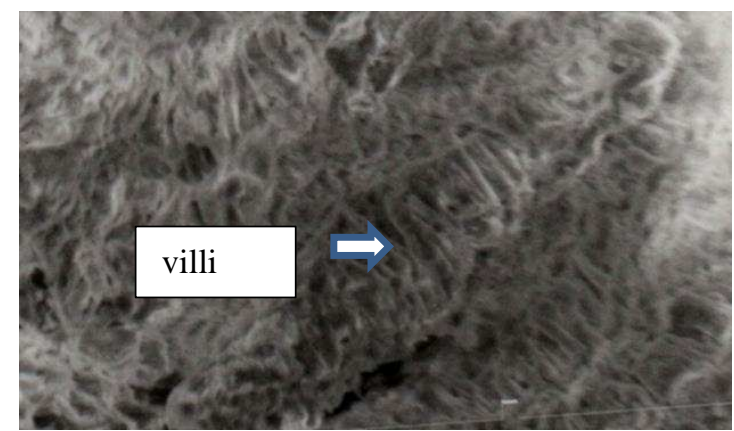

Fig 4. SEM images of the jejunal mucosa of the Control group using electron microscopy with 750x magnification

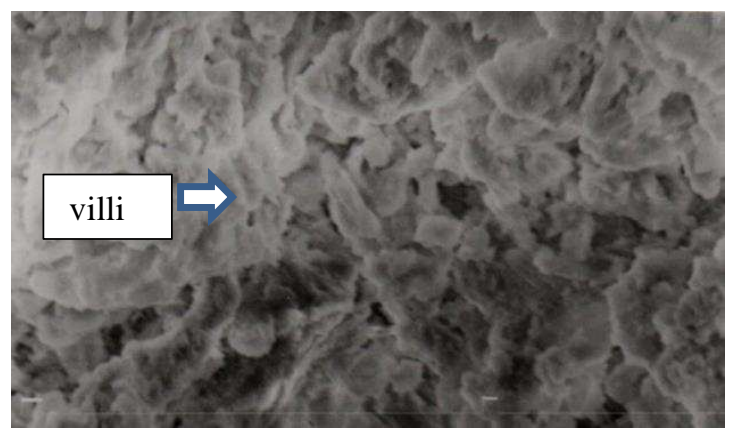

Fig 5. SEM images of the jejunal mucosa of the LPS group using electron microscopy with 750x magnification 


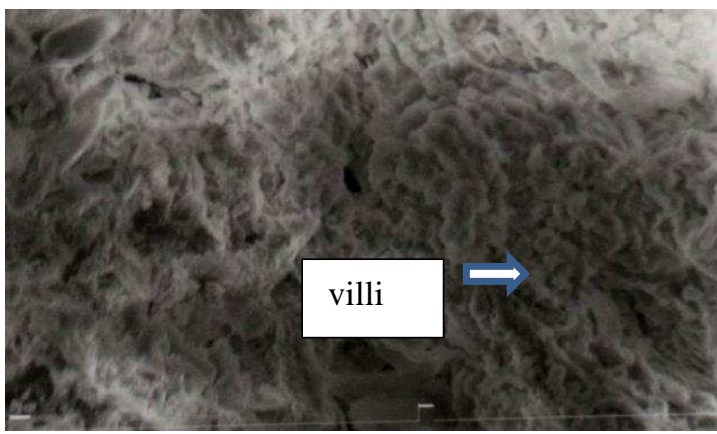

Fig 6. SEM images of the jejunal mucosa of the LPS-Zinc group using electron microscopy with 750x magnification

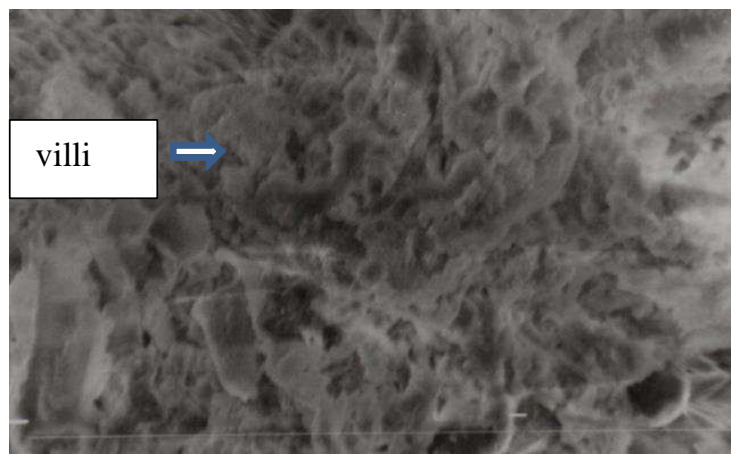

Fig 7. SEM images of the jejunal mucosa of the Zinc group using electron microscopy with 750x magnification

\section{Conclusion}

Oral administration of zinc decreased the expression of monocyte NFkB in an animal model of sepsis and improved the mucosal structure of the jejunum in an animal model of sepsis. The zinc mechanism in sepsis improvement is through inhibition of NFkB at 8 and 24 hours. Zinc inhibition of NFkB via the TGF- $\beta$ pathway at 72 hours.

\section{Acknowledgements}

We thank the Bioscience Institute of Brawijaya University for the expert advice and support throughout this research.

\section{References}

1. Weiss SL, Fitzgerald JC, Pappachan J, et al. Global epidemiology of pediatric severe sepsis: the sepsis prevalence, outcomes, and therapies study, American Journal of Respiratory and Critical Care Medicine, 2015, 191(10): 1147-1157. doi: 10.1164/rccm.201412$2323 \mathrm{OC}$

2. Southeast Asia Infectious Disease Clinical Research Network. Causes and outcomes of sepsis in southeast Asia: a multinational multicentre cross-sectional study, The Lancet Global Health. The Author(s). Published by Elsevier Ltd. This is an Open Access article 
under the CC BY 4.0 license, 2017, 5(2), pp. e157-e167. doi: 10.1016/S2214-109X(17)30007-4.

3. Irawan D, Hamidah, Purwanti, et al. Profil penderita sepsis akibat bakteri penghasil ESBL, Jurnal Penyakit Dalam, 2012, 13(1): 6368.

4. Ministry Of Health Indonesia. Pedoman Nasional Pelayanan Kedokteran Tatalaksana Sepsis, 2017.

5. Besecker BY, Exline MC, Hollyfield, et al. A comparison of zinc metabolism, inflammation, and disease severity in critically ill infected and noninfected adults early after intensive care unit admission, The American Journal of Clinical Nutrition, 2011, 93(6): 1356-1364. doi: 10.3945/ajen.110.008417

6. Heidemann SM, Holubkov R, Meert KL, et al. Baseline Serum Concentrations Of Zinc, Selenium, And Prolactin In Critically Ill Children, Pediatric Critical Care Medicine, 2011, 14(4): 202-206. doi: 10.1097/PCC.0b013e31827200f5

7. Helmy TA and Beshey BN. Correlation Between Serum Zinc And Mortality In Septic Patients, International Journal of Advanced Research, 2016, 4(4); 1514-1517. doi: 10.3390/nu10080976

8. Cohen J. The Immunopathogenesis Of Sepsis, Nature, 2002, 420(6917); 885-891. doi: 10.1038/nature01326.

9. Peters J and Cohen J. Sepsis, Medicine, 2013, 41(11): 667-669. doi: https://doi.org/10.1016/j.mpmed.2013.08.011

10. Liu SF and Malik AB. NF-Kappa B Activation As A Pathological Mechanism Of Septic Shock And Inflammation, American Journal of Physiology Lung Cellular and Molecular Physiology, 2006, 290(4): L622-45. doi: 10.1152/ajplung.00477.2005.

11. Wiest R and Rath HC. Gastrointestinal Disorders of Critically Ill Bacterial Translocation In The Gut, Best Practice \& Research Clinical Gastroenterology, 2003, 17(3): 397-425. doi: https://doi.org/10.1016/S1521-6918(03)00024-6

12. Al-Sadi R, Boivin M, and Ma T. Mechanism Of Cytokine Modulation Of Epithelial Tight Junction Barrier, Frontiers in Bioscience, 2009, 14(1): 2765-2778. doi: 10.2741/3413.

13. Balzan S, De Almeida Quadros C, De Cleva R, et al. Bacterial Translocation: Overview of Mechanisms and Clinical Impact Journal of Gastroenterol and Hepatology, 2007, 22(4): 464-471. doi: 10.1111/j.1440-1746.2007.04933.x.

14. Von Bülow V, Dubben S, Engelhardt G, et al. Zinc-Dependent Suppression Of TNF-Alpha Production Is Mediated By Protein Kinase A-Induced Inhibition Of Raf-1, I Kappa B Kinase Beta, And NF-Kappa B, The Journal of Immunology, 2007, 179(6): 4180-4186. doi: 10.4049/jimmunol.179.6.4180.

15. Powell SR. Zinc And Health: Current Status And Future Directions The Antioxidant Properties Of Zinc, The Journal of Nutrition, 2000, 130(5): 1488-1492. doi: 10.1093/jn/130.5.1447S

16. Bao B, Prasad A, Beck F. Zinc Decreases C-Reactive Protein, Lipid Peroxidation, And Implication Of Zinc As An Atheroprotective Agent, The American Journal of Clinical Nutrition, 2010, 91(6), pp. 1634-41. doi: 10.3945/ajcn.2009.28836. Epub 2010 Apr 28.

17. Song ZH, Xiao K, Ke YL, et al. Zinc Oxide Influences Mitogen-Activated Protein Kinase And TGF-B1 Signaling Pathways, And Enhances Intestinal Barrier Integrity In Weaned Pigs, Innate Immunity, 2015, 2(4): 341-348. doi: 10.1177/1753425914536450.

18. Dutra RL, Cantos GA, and Carasek E. Analysis Of Zinc In Biological Samples By Flame Atomic Absorption Spectrometry: Use Of Addition Calibration Technique, Biologial Trace Element Research, 2006, 111(1-3): 265-279. doi: 10.1385/BTER:111:1:265.

19. Smith JC, Butrimovitz GP, and Purdy WC. Direct Measurement Of Zinc In Plasma By Atomic Absorption Spectroscopy, Clinical Chemistry, 1979, 25(8): 1487-1491.

20. Habold C, Dunel-Erb S, Chevalier C, et al. Observations Of The Intestinal Mucosa Using Environmental Scanning Electron Microscopy (ESEM) Comparison With Conventional Scanning Electron Microscopy (CSEM), Micron, 2003, 34(8): 373-379. doi: 10.1016/S0968-4328(03)00080-5

21. Utomo M.T, Sudarmo S.M, Sudiana K. Zinc Supplementation in Cytokine Regulation During LPS-induced Sepsis in Rodent, Journal of International Dental and Medical Research, 2020 3(1): 46-50.

22. Yanagisawa H. Zinc Deficiency And Clinical Practice-Validity Of Zinc Preparations, The Journal of Japan Medical Association, 2004, 47(8): 359-364. doi: 10.1248/yakushi.128.333.

23. Yamasaki S, Sakata-Sogawa K, Hasegawa A, et al. Zinc Is A Novel Intracellular Second Messenger, Journal of Cell Biology, 2007, 177(4): 637-645. doi: 10.1083/jcb.200702081

24. Bao S, Liu M, Lee B, et al. Zinc Modulates The Innate Immune Response In Vivo To Polymicrobial Sepsis Through Regulation Of NF- Kb, American Journal of Physiology Lung Cellular and Molecular Physiology, 2010, 298: 744-755. doi: 10.1152/ajplung.00368.2009

25. Covert MW. Achieving Stability Of Lipopolysaccharide-Induced NF- Kb Activation, Science, 2005, 309(5742): 1854-1857. doi: 10.1126/science. 1112304 .

26. Prasad AS, Bao B, Beck FWJ, et al. Zinc-Suppressed Inflammatory Cytokines By Induction Of A20-Mediated Inhibition Of Nuclear Factor-Kb, Nutrition, 2011, 27(7-8): 816-823. doi: 10.1016/j.nut.2010.08.010

27. Bao B, Prasad AS, Beck FWJ, et al. Zinc up-regulates NF- kB activation via phosphorylation of Ik B in HUT-78 (Th0 ) cells, FEBS Letters, 2007, 581: 4507-4511. doi: 10.1016/j.febslet.2007.08.030

28. Li Q, Zhang Q, Wang C, et al. Disruption Of Tight Junctions During Polymicrobial Sepsis In Vivo, The Journal of Pathology, 2009, 218: 210-221. https://doi.org/10.1002/path.2525

29. Wang X, Carmen M, and Mullin JM. Zinc Supplementation Modifies Tight Junctions And Alters Barrier Function Of CACO-2 Human Intestinal Epithelial Layers, Digestive Disease and Science, 2013, 58: 77-87. doi: 10.1007/s10620-012-2328-8

30. Lodemann U, Einspanier, Scharfen F, et al. Effects Of Zinc On Epithelial Barrier Properties And Viability In A Human And A Porcine Intestinal Cell Culture Model, Toxicology in Vitro, 2013, 27(2): 834-843. doi: 10.1016/j.tiv.2012.12.019 